\title{
La incorporación de las TDIC en cursos de formación inicial de profesores: la experiencia de un curso de Licenciatura en Matemática
}

\author{
Monica Fürkotter ${ }^{1}$ \\ monicaf@unoeste.br \\ https://orcid.org/0000-0003-3479-5289 \\ Maria Raquel Miotto Morelatti ${ }^{2}$ \\ maria.raquel@unesp.br \\ https://orcid.org/0000-0001-5712-3237 \\ Eliel Constantino da Silva ${ }^{3}$ \\ elielconstantinosilva@gmail.com \\ https://orcid.org/0000-0003-3555-791X \\ ${ }^{1}$ Universidade do Oeste Paulista (Unoeste, Brasil) \\ ${ }^{2}$ Universidade Estadual Paulista (UNESP, Brasil) \\ ${ }^{3}$ Colégio Internacional Radial/Foreducation EdTech (Brasil)
}

Recibido: 31/05/2020 Aceptado: 17/07/2020

\begin{abstract}
Resumen
Buscando promover la capacitación de maestros de Matemática para el uso de las Tecnologías de Información y Comunicación Digital (TDIC), se realizaron cambios curriculares en el curso de Licenciatura en Matemática de la Unesp/Campus de Presidente Prudente, Brasil, para incorporar TDIC en el curso, para que los futuros licenciados puedan conocerlas y apropiarse de ellas. Dichos cambios comenzaron incluso antes de que la legislación lo mencionara. Apoyados en la legislación sobre la formación inicial de profesores para la Educación Básica, en el Conocimiento Tecnológico y Pedagógico de Contenido (TPACK), que identifica el conocimiento esencial para la práctica docente con tecnología y la visión de los graduados sobre la formación que experimentaron, presentamos los resultados de una investigación que tenía como objetivo analizar cómo se construye este conocimiento en la capacitación brindada por el curso. Es una investigación cualitativa, con un diseño descriptivo explicativo, que utilizó el análisis documental de la legislación sobre formación docente y el proyecto pedagógico del curso, así como un cuestionario aplicado a los graduados entre 2006 y 2017. Los resultados apuntan contribuciones de las experiencias durante la capacitación inicial al desempeño docente profesional, demostrando la apropiación crítica de TDIC en el proceso de enseñanza y aprendizaje de la Matemática.
\end{abstract}

Palabras clave: Formación de profesores de Matemática; Tecnologías Digitales de Información y Comunicación; TPACK; Educación Matemática.

\section{A incorporação das TDIC em cursos de formação inicial de professores: a experiência de um curso de Licenciatura em Matemática}

\section{Resumo}

Visando promover a formação de professores de Matemática para o uso das Tecnologias Digitais de Informação e Comunicação (TDIC) foram realizadas alterações curriculares no curso de Licenciatura em Matemática da Unesp/Câmpus de Presidente Prudente, Brasil, de modo a incorporar as TDIC no curso, para que o licenciando pudesse conhecer e se apropriar desses recursos. Tais modificações tiveram início antes mesmo que a legislação sobre 
formação de professores no contexto brasileiro mencionasse a tecnologia. Apoiados nas legislações sobre formação inicial de professores da Educação Básica, no Conhecimento Tecnológico e Pedagógico do Conteúdo (TPACK), que identifica conhecimentos essenciais para a prática docente com tecnologia e na visão de egressos sobre a formação vivenciada, apresentamos neste artigo resultados de uma pesquisa que teve por objetivo analisar como esses conhecimentos são construídos na formação propiciada pelo curso. Trata-se de uma pesquisa qualitativa, de delineamento descritivo explicativo, que utilizou análise documental da legislação sobre formação de professores e do projeto pedagógico do curso, bem como questionário aplicado à egressos do período 2006-2017. Os relatos dos respondentes revelam contribuições das vivências ao longo da formação inicial para a sua atuação profissional docente, que demonstram apropriação crítica das TDIC no processo de ensinar e aprender Matemática.

Palavras-chave: Formação de professores de Matemática; Tecnologias Digitais de Informação e Comunicação; TPACK; Educação Matemática.

\title{
TDIC's incorporation in initial teacher training courses: the experience of the degree in mathematics course
}

\begin{abstract}
In order to promote the training of Mathematics teachers on using Digital Information and Communication Technologies (DICT), curricular changes were made in the Degree in Mathematics course of the São Paulo State University (Unesp), School of Technology and Sciences, Presidente Prudente, Brasil, to incorporate DICT in the course, so that the licensee could know and appropriate these resources. This has started before the legislation on initial teacher training in the Brazilian context even mentioned technology. Supported by legislation on initial formation of teachers for Basic Education, on the Technological Pedagogical Content Knowledge (TPACK), which identifies teachers' key knowledge to their teaching practice with technology and the view of graduates on their training, we present the results of a research that intended to analyze how this knowledge is built in the training provided by the course. It's a qualitative research, with explanatory descriptive design, which used documentary analysis of the legislation on teacher training and the pedagogical project of the course, also a questionnaire applied to graduates from 2006-2017. Respondents' reports revealed the contribution from the experiences during the initial training to their professional performance, which demonstrate critical appropriation of DTIC in the process of teaching and learning Mathemathics.
\end{abstract}

Keywords: Mathematics teacher training; Digital Information and Communication Technologies; TPACK; Mathematics Education.

\section{Introdução}

Desde a década de 1970 pesquisadores de diferentes universidades brasileiras, motivados pelo uso das TDIC na Educação em outros países, como Estados Unidos da América e França (Valente, 1999) e pelas pesquisas relacionadas a isso, têm investigado esse uso no contexto educacional brasileiro antes mesmo que a legislação específica sobre formação inicial de professores explicitasse a importância da familiarização do licenciando 
com as TDIC, visando o seu uso para o aprimoramento da atuação docente e da aprendizagem dos alunos.

Entretanto, os projetos pedagógicos dos cursos de licenciatura nem sempre contemplam a formação para o uso das TDIC. Lopes e Fürkotter (2016, p. 271) desenvolveram pesquisas com o objetivo de "investigar se, na licenciatura, a formação do professor que atuará na Educação Básica contém conhecimento sobre TDIC e sob qual paradigma pedagógico os mesmos se articulam". Para tanto, analisaram "matrizes curriculares, programas de ensino e ementas de 123 cursos de formação docente" de três universidades estaduais do Estado de São Paulo, Brasil. Observaram "que o número de disciplinas optativas com ocorrência de TDIC é maior que o número de disciplinas obrigatórias (...), podendo ser este um indício de como a formação para o uso das TDIC se encontra no currículo formal das universidades pesquisadas" (Lopes \& Fürkotter, 2016, p. 279). Assim, quando presentes, as TDIC estão em disciplinas optativas, caracterizando-se pela não intencionalidade e pelo interesse do docente formador, como revelam as pesquisas de Lopes $(2010,2014)$ e Lopes e Fürkotter (2016).

Não é o que ocorre com o curso analisado neste artigo, que desde 2005, oportuniza aos licenciandos, durante os quatro anos de formação, experiências com TDIC, que contribuem na constituição dos conhecimentos de conteúdo específico, pedagógico e tecnológico que fundamentarão a sua futura atuação docente.

As TDIC estão presentes na sociedade contemporânea, uma parcela significativa de jovens brasileiros tem contato direto e familiaridade com elas praticamente desde o seu nascimento e,

As instituições de ensino, tanto do ensino básico quanto do superior, precisam estar conscientes de como as tecnologias digitais estão mudando e como elas estão alterando os processos de ensino e de aprendizagem. (...) o aluno já não é mais o mesmo e não atua como antes. (Valente, 2018, p. 17)

Entretanto, ainda que os licenciandos façam uso da tecnologia no seu dia a dia, é preciso fazer com que vivenciem seu uso para aprender Matemática, de modo que venham a perceber as possibilidades de utilizá-la na sua futura prática docente.

Nessa perspectiva de uso da tecnologia, para aprender e ensinar Matemática, segundo o projeto pedagógico vigente, os alunos têm contato com a tecnologia em diversas disciplinas do curso para aprender “(...) de e sobre matemática” (Ball, 1988, p.39). Por conhecimento de Matemática entendemos conceitos, proposições e procedimentos 
matemáticos, incluindo aqui também formas de representar a Matemática para que outros possam entendê-la e, por conhecimento sobre Matemática, ideias sobre o que é a Matemática, de onde vem, para que serve, seu papel e importância.

A vivência com TDIC no curso habilita os licenciandos para, no último ano, cursar uma disciplina, que prevê o desenvolvimento de projetos de intervenção em escolas públicas utilizando TDIC. Tais projetos oportunizam a reflexão sobre porquê e como utilizá-las para ensinar Matemática e levam os alunos a ressignificar as experiências, os conhecimentos e os modelos vivenciados durante o processo de formação. Assim, o futuro professor tem a possibilidade de interagir com as TDIC, de forma diversificada, para aprender e para ensinar Matemática, para refletir e para discutir criticamente o seu uso na futura atuação docente.

Desse modo, há 15 anos, a formação inicial proposta pelo curso contempla a incorporação e utilização das TDIC, como recurso pedagógico, articulando os diferentes conhecimentos na perspectiva do Conhecimento Tecnológico e Pedagógico do Conteúdo (TPACK), promovendo o desenvolvimento pessoal e profissional do futuro professor.

Tal experiência nos levou a desenvolver uma pesquisa com o objetivo de analisar como esses conhecimentos são construídos no processo de formação propiciado pelo curso. Trata-se de uma pesquisa qualitativa, de delineamento descritivo explicativo, que analisou a legislação sobre formação de professores, o projeto pedagógico do curso e dados oriundos de um questionário aplicado à egressos do período 2006-2017.

Neste artigo apresentamos resultados dessa pesquisa, que permitem discutir a incorporação das TDIC no processo de formação inicial de professores na Licenciatura em Matemática da Universidade Estadual Paulista (Unesp), Faculdade de Ciências e Tecnologia, Câmpus de Presidente Prudente, Brasil, a partir do que está posto sobre tecnologia na legislação que fundamenta a Educação Básica brasileira e a formação de professores, assim como do que as pesquisas revelam sobre a formação para o uso das TDIC.

Acreditamos que os resultados dessa pesquisa podem inspirar outras instituições de ensino superior quanto a incorporação das TDIC na formação docente.

\section{Formação inicial de professores para o uso de TDIC}

Saber incorporar as TDIC à prática pedagógica é, atualmente, essencial ao professor, tendo em vista o cenário social em que estamos imersos, no qual conceitos tais como 
pervasividade, convergência digital, educação ubíqua e m-learning, advindos da Web 3.0, a chamada rede semântica, se fazem presentes.

Para tanto, o professor deve dominar o Technological Pedagogical Content Knowledge, ou Conhecimento Tecnológico e Pedagógico do Conteúdo, que propragou-se em 2005 por Mishra e Koehler por meio da sigla TPCK, alterada para TPACK em 2008. Tal conhecimento está fundamentado na base de conhecimentos do professor para o ensino (Shulman, 1986), mais especificamente, no Conhecimento Pedagógico de Conteúdo, identificado por Pedagogical Content Knowledge (PCK), que envolve Conhecimento de Conteúdo (CK) e Conhecimento Pedagógico (PK). Ao PCK, Mishra e Koehler (2006) associaram o Conhecimento Tecnológico (TK), de modo que esses conhecimentos devem estar mobilizados pelo professor em contextos de ensino, como mostra o diagrama da Figura 1.

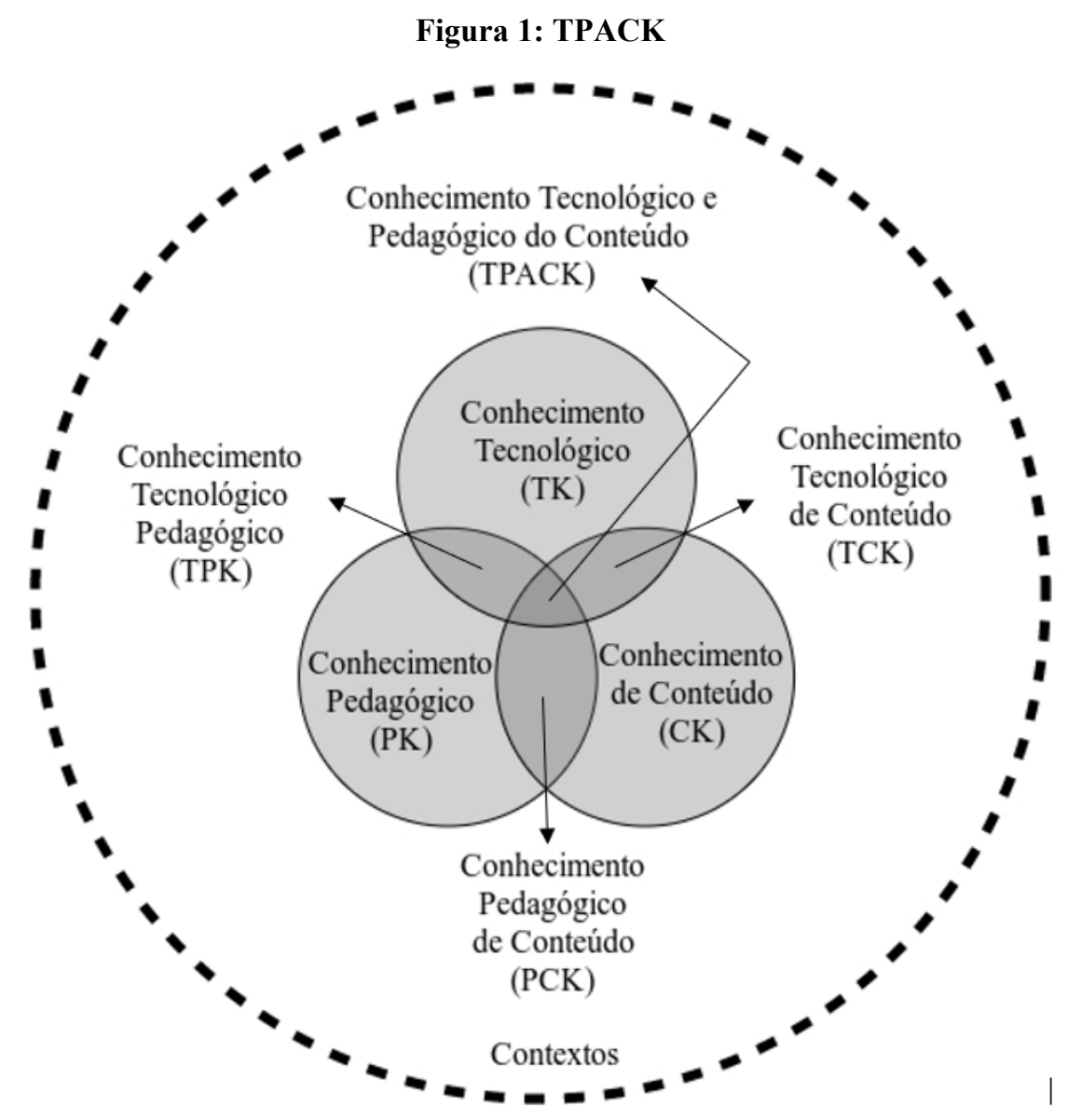

Fonte: Adaptado de Koehler et al. (2014, p. 9)

O PK e o TK constituem o Conhecimento Tecnológico Pedagógico (TPK), “definido como a compreensão de qual seja a melhor forma de o professor utilizar determinadas tecnologias para desenvolver os procedimentos de ensino e aprendizagem" (Cibotto \& Oliveira, 2017, p. 17). Por sua vez, o TK e o CK originam o Conhecimento Tecnológico do 
Conteúdo (TCK), que "representa o conhecimento de ferramentas tecnológicas e representações que são usadas em uma disciplina" (Cibotto \& Oliveira, 2017, p. 18). O PK e o CK formam o Conhecimento Pedagógico de Conteúdo (PCK), "que pode ser considerado a capacidade de ensinar um determinado conteúdo curricular observando o conhecimento prévio dos alunos" (Cibotto \& Oliveira, 2017, p. 16).

O TPACK, ao articular os diferentes conhecimentos e considerar o contexto no qual o ensino e a aprendizagem são realizados,

Representa a utilização da tecnologia para apoiar estratégias pedagógicas específicas e construtivas para ensinar o conteúdo, devidamente adequadas às necessidades e às preferências dos alunos, exigindo dos professores flexibilidade e fluência do conteúdo curricular (o assunto a ser aprendido e ensinado), da pedagogia (os processos, práticas, estratégias, procedimentos e os métodos de ensino e aprendizagem), da tecnologia (tanto as tradicionais quanto as mais avançadas como os computadores, internet e softwares) e do contexto envolvido, salientando a complexa interação desses três corpos de conhecimento, em que cada um influencia diretamente o outro. (Cibotto \& Oliveira, 2017, p. 19-20)

Tão importante quanto identificar os diferentes conhecimentos articulados no TPACK é refletir sobre como eles se constroem durante um curso de licenciatura. O maior desafio "na formação dos professores e dos formadores é sem dúvida conseguir suscitar uma mudança conceptual na sua relação com o saber e a sua elaboração” (Barth, 1993, p. 13). Isso porque “(...) a experiência como aluno, não apenas no curso de formação docente mas ao longo de toda a sua trajetória escolar, é constitutivo do papel que exercerá futuramente como docente" (Pires, 2002, p. 48).

Ao entendermos que elaboramos as nossas "teorias" a partir do vivido enquanto educandos, que nossos saberes se transformam com o tempo, a partir da reflexão e da troca coletiva de experiências, precisamos modificar e alargar a percepção intuitiva dos alunos (Barth, 1993), o que:

(...) aponta para a necessidade de que o futuro professor experiencie, como aluno, durante todo o processo de formação, as atitudes, modelos didáticos, capacidades e modos de organização que se pretende que venha a ser desempenhado nas suas práticas pedagógicas. Ninguém promove o desenvolvimento daquilo que não teve oportunidade de desenvolver em si mesmo. (Pires, 2002, p. 48)

Cabe alargar o exposto acima, de modo a incluir a necessidade do licenciando experienciar, durante todo o processo de formação, a utilização das TDIC para aprender conteúdos de e sobre Matemática (Ball, 1988). Corroboramos com Santos et al. (2017) ao defenderem que a "formação inicial é uma fase importante na docência. É a partir dela que 
os futuros professores adquirem conhecimentos e capacidades para trabalharem na educação básica" (Santos et al., 2017, p. 266).

Entretanto, a pesquisa de Lopes e Fürkotter (2016) revela que, nos cursos de licenciatura das universidades estaduais paulistas, em geral, isso não ocorre, ao constatar a ocorrência das tecnologias marcadamente em disciplinas optativas dos cursos, não assegurando a formação a todos os licenciandos. Quando nos referimos à formação inicial do professor no tocante a incorporação das TDIC para a atuação profissional após o período de formação, um dos problemas é a "estrutura fechada e disciplinar com que os programas são construídos" (Kenski, 2013, p. 73), o que nos leva a defender, assim como Paiva et al. (2012), que é necessário rever a formação docente para que eles consigam incorporar as TDIC em sua prática.

Assim como Almeida (2015), compreendemos que “"atrair' ou 'sensibilizar' os professores para a (re)invenção do processo de ensino e aprendizagem de Matemática a partir do uso da informática é um processo lento e vários fatores concorrem para sua concretização" (Almeida, 2015, p. 234), como por exemplo, as experiências com TDIC durante a formação inicial.

É nessa perspectiva que o curso que se investigou em pesquisa, cujos resultados apresentamos neste artigo, está consolidado e difere do revelado por Lopes e Fürkotter (2016) na medida em que as TDIC estão incorporadas no processo de formação inicial docente há 15 anos.

\section{Legislação sobre formação inicial de professores e o uso de TDIC}

Segundo Coll et al. (2010, p. 15), a sociedade atual "comporta novas maneiras de trabalhar, de comunicar-se, de relacionar-se, de aprender, de pensar e, em suma, de viver", o que demanda determinadas competências profissionais docentes. Uma delas é saber utilizar as tecnologias, não para fazer o mesmo, mas para fazer o diferente, para desenvolver processos de ensino e aprendizagem que não seriam possíveis sem elas (Perrenoud, 2000). Isso requer modificar "as práticas educacionais nas quais são incorporadas" (Coll et al., 2010, p. 66), originando um desafio para as instituições de ensino superior que formam professores que venham responder aos anseios e às práticas da sociedade atual.

Nosso interesse pela formação de professores para o uso das TDIC nos levou a buscar e acompanhar, desde 1996, como a tecnologia está presente na legislação educacional 
brasileira, nos conduzindo a perceber que as TDIC são abordadas nos documentos oficiais segundo diferentes ângulos.

A Lei de Diretrizes e Bases da Educação Nacional (LDB), Lei n ${ }^{\circ}$. 9.394/96, estabelece em seu Art. 32, inciso II, que o Ensino Fundamental tem como objetivo a formação básica do cidadão, mediante "a compreensão do ambiente natural e social, do sistema político, da tecnologia, das artes e dos valores em que se fundamenta a sociedade" (Lei nº 9394, 1996, p. 12).

Segundo as Diretrizes Curriculares Nacionais para o Ensino Médio, instituídas pela Resolução da Câmara de Educação Básica (CEB), nº. 3/1998, os currículos devem ser organizados em áreas do conhecimento que permitam ao educando a constituição de competências e habilidades, entre elas compreender e aplicar a tecnologia e entender o seu impacto na sociedade (Resolução $n^{0} 3$, 1998).

Os Parâmetros Curriculares Nacionais (PCN) também abordam as tecnologias, considerando-as como agente de transformação da sociedade e indicando que "o uso desses recursos traz significativas contribuições para repensar sobre o processo de ensino e aprendizagem de Matemática" (Brasil, 1998, p. 43).

Porém, a formação para o uso das tecnologias não estava até então contemplada na legislação sobre a formação inicial de professores. Somente em 2001, no Plano Nacional de Educação, é indicado o "domínio das tecnologias de comunicação e informação e capacidade para integrá-las à prática do magistério" (Lei n 010172, 2001a, p. 65) como um dos princípios a que os cursos de formação deveriam se submeter, em todos os níveis e modalidades.

Some-se a isso o Parecer do Conselho Nacional de Educação/Câmara de Educação Superior (CNE/CES) $n^{\circ} .1 .302 / 2001$, sobre as Diretrizes Curriculares Nacionais para os Cursos de Matemática, Bacharelado e Licenciatura, que explicita como uma das competências e habilidades que os currículos dos cursos devem desenvolver a "capacidade de compreender, criticar e utilizar novas ideias e tecnologias para a resolução de problemas" (Parecer $n^{\text {o } 1302, ~ 2001 b, ~ p . ~ 3) . ~}$

Desde o início do curso o licenciando deve adquirir familiaridade com o uso do computador como instrumento de trabalho, incentivando-se sua utilização para o ensino de matemática, em especial para a formulação e solução de problemas. É importante também a familiarização do licenciando, ao longo do curso, com outras tecnologias que possam contribuir para o ensino de Matemática. (Parecer nº 1302, 2001b, p. 6) 
A Resolução do Conselho Nacional de Educação/Conselho Pleno (CNE/CP), nº. 1/2002, que institui as Diretrizes Curriculares Nacionais para a Formação de Professores da Educação Básica, em nível superior, curso de licenciatura, de graduação plena, em seu Artigo $2^{\circ}$., propõe que a organização curricular de cada instituição deverá observar "outras formas de orientação inerentes à formação para a atividade docente, entre as quais o preparo para (...) o uso de tecnologias da informação e da comunicação e de metodologias, estratégias e materiais de apoio inovadores" (Resolução $\mathrm{n}^{0}$ 1, 2002a, p. 1). Além disso, a prática profissional no processo formativo "poderá ser enriquecida com tecnologias de informação, incluídos o computador e o vídeo" (Resolução n 2, 2002b, p. 6).

Entendemos que essa resolução apresenta um avanço ao instituir que os projetos pedagógicos dos cursos efetivem a integralização da carga horária mínima de 2800 horas, garantindo que a articulação teoria-prática ocorra nas quatro dimensões dos componentes comuns, quais sejam, prática como componente curricular, estágio curricular supervisionado, conteúdos curriculares de natureza científico-cultural e atividades acadêmico-científico-culturais. Some-se a isso o parágrafo $1^{\circ}$. do Art. 12 , segundo o qual, "A prática, na matriz curricular, não poderá ficar reduzida a um espaço isolado, que a restrinja ao estágio, desarticulado do restante do curso".

Assim, entendemos que se os projetos pedagógicos dos cursos atenderem a resolução na sua plenitude, propiciarão ao licenciando a articulação do Conhecimento de Conteúdo, do Conhecimento Pedagógico, propostos por Shulman (1986), ao Conhecimento Tecnológico na perspectiva do TPACK.

Por acreditarmos que essa articulação é indispensável na formação do futuro professor de Matemática, causou-nos preocupação o Parecer CNE/CP 9/2007, sobre "Reorganização da carga horária mínima dos cursos de Formação de Professores, em nível superior, para a Educação Básica e Educação Profissional no nível da Educação Básica" (Parecer $n^{\circ}$ 9, 2007). Tal parecer indicava a revogação da Resolução CNE/CP nº. 2/2002, que estabelecia a carga horária de cada uma das quatro dimensões dos componentes comuns, sendo que do mínimo de 2800 horas, pelo menos 300 horas deveriam ser destinadas ao estágio supervisionado e pelo menos 2500 horas dedicadas às demais atividades formativas, sem explicitar a carga horária destinada à dimensão da prática como componente curricular.

Felizmente esse parecer não foi aprovado e novas diretrizes curriculares nacionais para a formação inicial em nível superior e para a formação continuada foram instituídas na 
Resolução CNE/CP n ${ }^{\circ}$. 2/2015, na qual a formação para o uso das tecnologias também está presente. $\mathrm{O}$ Art. $5^{\circ}$. prevê que a formação de profissionais do magistério deve compreender o "uso competente das Tecnologias de Informação e Comunicação (TIC) para o aprimoramento da prática pedagógica e a ampliação da formação cultural dos(as) professores(as) e estudantes" (Resolução n 2, 2015, p. 6). Segundo o Art. 13, a carga horária é ampliada para 3200 horas e continuam asseguradas as 400 horas de prática como componente curricular e 400 horas de estágio supervisionado. $\mathrm{O}$ inciso $\mathrm{V}$ do parágrafo $5^{\circ}$. do Art. $3^{\circ}$. estabelece como um dos princípios da Formação de Profissionais do Magistério da Educação Básica "a articulação entre a teoria e a prática no processo de formação docente, fundada no domínio dos conhecimentos científicos e didáticos, contemplando a indissociabilidade entre ensino, pesquisa e extensão" (Resolução n 2, 2015).

Assim, se a formação deve compreender o "uso competente das Tecnologias de Informação e Comunicação (TIC) para o aprimoramento da prática pedagógica e a ampliação da formação cultural dos(as) professores(as) e estudantes" (Resolução n 2, 2015, p. 6), o processo formativo, deve, necessariamente, contemplar a articulação dos diferentes conhecimentos na perspectiva do TPACK.

Mais recentemente, a Resolução CNE/CP nº. 2/2019 revoga a Resolução CNE/CP $n^{\circ}$. 2/2015 ao definir novas Diretrizes Curriculares Nacionais para a Formação de Professores da Educação Básica e instituir a Base Nacional Comum para a Formação Inicial de Professores da Educação Básica (BNC-Formação). À luz da Base Nacional Comum Curricular da Educação Básica (BNCC), a resolução define dez competências gerais docentes e uma delas, a de número cinco, é:

Compreender, utilizar e criar tecnologias digitais de informação e comunicação de forma crítica, significativa, reflexiva e ética nas diversas práticas docentes, como recurso pedagógico e como ferramenta de formação, para comunicar, acessar e disseminar informações, produzir conhecimentos, resolver problemas e potencializar as aprendizagens. (Resolução n 2, 2019, p. 13)

Quanto as competências específicas, estão atreladas a três dimensões: conhecimento profissional, prática profissional e engajamento profissional. Tais dimensões são interdependentes e não hierárquicas, devem se integrar e complementar a ação docente e a elas estão vinculadas competências e habilidades (Resolução nº 2, 2019).

Apresenta-se no Quadro 1 as dimensões, as competências e as habilidades relacionadas às tecnologias. 
Quadro 1: Dimensões, competências e habilidades relacionadas às tecnologias na Resolução CNE/CP 2/2019

\begin{tabular}{|c|c|c|}
\hline Dimensões & Competências & Habilidades \\
\hline \multirow[t]{2}{*}{$\begin{array}{l}\text { Prática } \\
\text { profissional }\end{array}$} & $\begin{array}{l}\text { Planejar ações de ensino que } \\
\text { resultem em efetivas aprendizagens }\end{array}$ & $\begin{array}{l}\text { Realizar a curadoria educacional, utilizar as } \\
\text { tecnologias digitais, os conteúdos virtuais e } \\
\text { outros recursos tecnológicos e incorporá-los à } \\
\text { prática pedagógica, para potencializar e } \\
\text { transformar as experiências de aprendizagem } \\
\text { dos estudantes e estimular uma atitude } \\
\text { investigativa. }\end{array}$ \\
\hline & $\begin{array}{l}\text { Conduzir as práticas pedagógicas } \\
\text { dos objetos do conhecimento, das } \\
\text { competências e habilidades }\end{array}$ & $\begin{array}{l}\text { Usar as tecnologias apropriadas nas práticas de } \\
\text { ensino }\end{array}$ \\
\hline \multirow[t]{2}{*}{$\begin{array}{l}\text { Engajamento } \\
\text { profissional }\end{array}$} & $\begin{array}{l}\text { Comprometer-se com a } \\
\text { aprendizagem dos estudantes e } \\
\text { colocar em prática o princípio de } \\
\text { que todos são capazes de aprender }\end{array}$ & $\begin{array}{l}\text { Atentar nas diferentes formas de violência } \\
\text { física e simbólica, bem como nas } \\
\text { discriminações étnico-racial praticadas nas } \\
\text { escolas e nos ambientes digitais, além de } \\
\text { promover o uso ético, seguro e responsável das } \\
\text { tecnologias digitais. } \\
\text { Construir um ambiente de aprendizagem que } \\
\text { incentive os estudantes a solucionar problemas, } \\
\text { tomar decisões, aprender durante toda a vida e } \\
\text { colaborar para uma sociedade em constante } \\
\text { mudança. }\end{array}$ \\
\hline & $\begin{array}{l}\text { Engajar-se, profissionalmente, com } \\
\text { as famílias e com a comunidade }\end{array}$ & $\begin{array}{l}\text { Saber comunicar-se com todos os } \\
\text { interlocutores: colegas, pais, famílias e } \\
\text { comunidade, utilizando os diferentes recursos, } \\
\text { inclusive as tecnologias da informação e } \\
\text { comunicação. }\end{array}$ \\
\hline
\end{tabular}

Fonte: Adaptado da Resolução CNE/CP nº. 2/2019

A resolução mantém a carga horária mínima de 3200 horas para integralização do curso e de 400 horas para a prática dos componentes curriculares distribuídas ao longo do curso, desde o seu início (Resolução nº 2, 2015).

Assim, o Projeto Pedagógico dos cursos de licenciatura no Brasil deve se comprometer com a educação integral dos professores em formação, abarcando a utilização e criação apropriada das TDIC como ferramenta de formação e comunicação em suas práticas de ensino, de modo a contemplar as habilidades apresentadas no Quadro 1. Para tanto, defendemos que o aluno deve experienciar, durante todo o processo formativo, a utilização das tecnologias como apoio a estratégias pedagógicas para ensinar os diferentes conteúdos, mais uma vez na perspectiva no quadro teórico do TPACK.

No caso específico do Estado de São Paulo, Brasil, a Deliberação nº. 111/2012 (2012) do Conselho Estadual de Educação (CEE) fixa as diretrizes curriculares complementares para a formação de docentes da Educação Básica, oferecida pelos estabelecimentos de ensino superior vinculados ao sistema estadual paulista. Ainda que tal deliberação tenha sido alterada em alguns de seus dispositivos pela Deliberação CEE $n^{0}$. 126/2014, ambas estabelecem em seu Artigo $5^{\circ}$. que a formação de docentes para os anos finais do Ensino 
Fundamental e para o Ensino Médio incluirá na estrutura curricular conteúdos voltados para a "utilização das Tecnologias de Informação e Comunicação (TICs) como recurso pedagógico e para o desenvolvimento pessoal e profissional" (Deliberação 126, 2014, p. 3).

De modo a atender o disposto na Resolução CNE/CP n ${ }^{0}$. 2/2015, em 2017, a Deliberação CEE no ${ }^{\circ}$ 154/2017, altera a redação da Deliberação CEE nº ${ }^{\circ}$ 111/2012. Além de manter o conteúdo descrito em relação as TICs, explicita em seu Art. $8^{\circ}$., inciso I, que, dentre as 3200 horas da carga horária mínima total do curso, 200 delas devem ser necessariamente dedicadas à revisão de conteúdos curriculares, Língua Portuguesa e Tecnologia de Informação e Comunicação (TIC). Assim, a legislação elucida e amplia a preocupação com a formação do futuro professor para o uso das TDIC. Segundo a deliberação, a Prática como Componente Curricular (PCC):

(...) é facilitadora da interdisciplinaridade, ou seja, não acontece apenas no âmbito de um componente curricular mas na interação entre as dimensões teóricas ou práticas de dois ou mais conteúdos disciplinares, na forma de projetos de estudo e investigação, projetos de intervenção ou de produção. Aqui se inclui a articulação entre dois ou mais conteúdos específicos ou entre estes e os de conhecimentos pedagógicos. O importante para este conceito de PCC, é que nessa abordagem a articulação entre as disciplinas deve ser feita a partir do domínio pedagógico dos conteúdos das mesmas, caracterizando a PCC das disciplinas envolvidas. (Deliberação 154, 2017)

A deliberação está fundamentada na base de conhecimentos de Shulman, e juntamente com o disposto no inciso I do Art. $8^{\circ}$., remete ao TPACK.

Dado que a legislação contempla a formação para o uso da tecnologia, cabe questionar se os cursos de formação de professores atendem à legislação e como isso ocorre. A pesquisa realizada, que aqui se apresenta, analisa como os conhecimentos são construídos na formação propiciada pelo curso de Licenciatura em Matemática da Unesp/Câmpus de Presidente Prudente, Brasil.

\section{TDIC incorporadas à formação inicial de professores de Matemática: a experiência do curso de Licenciatura em Matemática da Unesp/Câmpus de Presidente Prudente}

O que professores de Matemática precisam saber para ensinar e para que esse ensino conduza à aprendizagem matemática? Essa é uma questão que tem norteado a formação de professores proposta e desenvolvida pelo curso de Licenciatura em Matemática da Unesp/Câmpus de Presidente Prudente.

Desde a sua criação, em 1963, o curso já formou um total de 1433 professores de Matemática, que atuam tanto no Ensino Fundamental e Médio, quanto em universidades no 
Brasil, públicas e privadas, e no exterior. Ao longo de mais de cinquenta e cinco anos de existência, já passou por diferentes reestruturações curriculares, que visaram atender à legislação brasileira sobre formação de professores bem como às demandas contemporâneas. No que se refere especificamente à formação para o uso das TDIC, cabe ressaltar que alterações curriculares foram realizadas, pautadas em pesquisas sobre o tema, antes mesmo das diretrizes oficiais previstas em legislação específica sobre a formação inicial de professores.

A reestruturação curricular realizada em 2005 trouxe mudanças significativas no curso. Além de atender a legislação nacional vigente à época sobre formação de professores da Educação Básica, Resoluções CNE/CP nº. 01/2002 e nº. 02/2002, bem como as Diretrizes Curriculares Nacionais para os Cursos de Matemática, Bacharelado e Licenciatura, tratadas no Parecer CNE/CES n ${ }^{\circ}$. 1.302/2001, atendeu aos anseios de discentes, docentes e do Conselho do Curso, fruto de um processo de avaliação interna. Para turmas ingressantes a partir de 2015, ocorreu nova reestruturação curricular, de modo a atender aos requisitos legais e normativos relativos às Diretrizes Curriculares Nacionais para Educação das Relações Étnico-Raciais e para o ensino de História e Cultura Afro-brasileira, africana e indígena, políticas de Educação Ambiental, desenvolvimento nacional sustentável, Diretrizes Nacionais para a Educação em Direitos Humanos e Diretrizes Nacionais para a Educação Especial na Educação Básica, bem como a legislação complementar do estado de São Paulo sobre formação de professores, Deliberação CEE $n^{\circ}$. 111/2012, alterada pela Deliberação CEE nº. 126/2014.

Dentre as alterações, destacam-se: carga horária de prática como componente curricular em todos os semestres do curso, em diferentes disciplinas, tanto de conhecimentos específicos de Matemática, quanto de conhecimento pedagógico do conteúdo e curricular; nova concepção e organização do estágio supervisionado, entendido como processo de inserção do futuro professor na comunidade escolar, tendo como natureza a compreensão e problematização da ação de ensinar; criação das disciplinas obrigatórias "Fundamentos de Matemática Elementar", "Programação Orientada a Sistemas de Computação Simbólica", “Laboratório de Ensino de Matemática I", "Laboratório de Ensino de Matemática II", "Informática no Ensino de Matemática" e "Seminários Especiais"; articulação de disciplinas, como por exemplo "Psicologia da Educação" e "Laboratório de Ensino de Matemática I", por meio de projetos interdisciplinares e/ou atividades; professor articulador, escolhido entre os professores das disciplinas de cada ano, responsável pela articulação das atividades 
práticas numa perspectiva interdisciplinar; oferta de, no mínimo, três disciplinas optativas, sendo obrigatoriamente pelo menos uma da área de Educação Matemática.

Em uma análise do projeto pedagógico do curso, realizada após a alteração curricular de 2005, a formação proposta, e ainda vigente, foi considerada "um modelo híbrido de formação que supera os modelos segmentado consecutivo e segmentado concorrente, com possibilidade de se aproximar do modelo colaborativo" (Fürkotter \& Morelatti, 2007, p. 331), por contemplar uma articulação dos docentes que trabalham em disciplinas de um mesmo semestre em projetos que envolvem situações-problema do contexto escolar. Para Marcelo Garcia (1999), no modelo segmentado concorrente a formação específica e a pedagógica são concomitantes e, no segmentado consecutivo, tem-se inicialmente o conhecimento geral e especializado e, posteriormente, os conhecimentos profissionais (pedagógicos). No modelo colaborativo, apesar das especificidades das disciplinas, há integração entre elas.

Outro avanço a ser destacado:

(...) é a presença da componente prática no bojo das disciplinas de conteúdo específico ou pedagógico, uma vez que a solução encontrada por muitas instituições para atender à legislação vigente foi a criação de disciplinas estanques, que não enfrentam um problema crucial dos cursos de formação de professores, qual seja, a articulação entre teoria e prática. (Fürkotter \& Morelatti, 2007, p. 331)

Quanto às TDIC, especificamente, destaca-se no curso sua integração em diferentes disciplinas que compõem a base do conhecimento da docência, na busca de desenvolver o Conhecimento Tecnológico e Pedagógico do Conteúdo (TPACK) do futuro professor de Matemática.

Já no início do curso, o aluno tem a possibilidade de superar deficiências em sua formação matemática básica, advindas do Ensino Fundamental e Médio, por meio de um conjunto de disciplinas que discutem conteúdos matemáticos na perspectiva do seu ensino na Educação Básica, sendo uma delas "Fundamentos de Matemática Elementar". Com isso, adquire um sólido domínio dos conceitos básicos, que serão objeto de sua futura prática docente, e tem subsídios para pensar em alternativas metodológicas, inclusive com o uso de tecnologias, para a transposição didática desses conceitos. Assim, tais disciplinas envolvem o Conhecimento de Conteúdo (CK) e o Conhecimento Pedagógico de Conteúdo (PCK).

As turmas ingressantes de 2005 a 2014 tinham contato direto e intencional com as TDIC na disciplina "Programação Orientada a Sistemas de Computação Simbólica", ao se 
familiarizarem com o software de Computação Algébrica MATLAB e/ou GNU Octave. Cabe esclarecer que, na reestruturação vigente, a partir de 2015, o conteúdo dessa disciplina foi incorporado à “Cálculo Numérico I", já existente, com adequações do conteúdo. Nelas, espera-se que o futuro professor conheça as principais ferramentas do software e se aproprie de noções sobre lógica de programação de modo a desenvolver o pensamento algorítmico para aplicá-las na resolução de problemas típicos de disciplinas de conteúdos matemáticos do curso, tais como "Cálculo Diferencial e Integral", "Geometria Analítica e Vetores", “Álgebra Linear”, "Equações Diferenciais Ordinárias”, entre outras. Com isso, o aluno utiliza o computador para aprender conteúdos de e sobre Matemática, tendo a possibilidade de desenvolver o Conhecimento Tecnológico (TK) e o Conhecimento Tecnológico de Conteúdo (TCK).

Outras duas disciplinas merecem destaque, "Laboratório de Ensino de Matemática I" e "Laboratório de Ensino de Matemática II". A primeira disciplina, do quarto semestre do curso, está relacionada aos anos finais do Ensino Fundamental enquanto a segunda, do oitavo e último semestre do curso, ao Ensino Médio. Um dos objetivos das disciplinas é elaborar situações de ensino e aprendizagem de conceitos matemáticos, com o uso de metodologias e recursos diversificados, incluindo as TDIC, e refletir sobre as potencialidades e limites de tais metodologias e recursos. Tais disciplinas promovem o desenvolvimento do Conhecimento Pedagógico (PK) e Conhecimento Tecnológico e Pedagógico (PCK).

Para turmas ingressantes até 2004, a estrutura curricular contava com a disciplina optativa "Ensino de Matemática por Múltiplas Mídias". Por ocasião da reestruturação do curso, essa disciplina tornou-se obrigatória e teve sua denominação alterada para "Informática no Ensino de Matemática". Porém, sua ementa e seus objetivos não foram modificados. Nessa disciplina, no último ano do curso, os licenciandos examinam diversos tipos de software educacional, bem como ambientes virtuais de aprendizagem. Ao mesmo tempo, realizam estudos sobre abordagens pedagógicas com TDIC, refletem e discutem o uso e os impactos das TDIC no processo ensino e aprendizagem de conceitos matemáticos. Além disso, propõem e desenvolvem um projeto de intervenção, com TDIC, no contexto das escolas públicas de Ensino Fundamental e Médio. Nesse projeto, partem de um conceito matemático, realizam estudo teórico do conceito, escolhem uma TDIC, elaboram uma sequência didática para ensinar tal conceito com a TDIC escolhida, vivenciam o desenvolvimento da sequência com os alunos, refletem, analisam e compartilham a experiência vivenciada. 
O Estágio Curricular Supervisionado, alocado em disciplinas a partir do quinto semestre do curso, estimula e aviva a investigação, a problematização, a ação e a reflexão, em situações reais do contexto escolar, inclusive com TDIC, a partir da inserção do futuro professor na escola básica. Há uma articulação entre disciplinas, entre elas, Laboratório de Ensino de Matemática I, Laboratório de Ensino de Matemática II e Informática no Ensino de Matemática, que fundamenta a ação e a reflexão dos alunos nos estágios.

As alterações introduzidas na estrutura curricular do curso a partir de 2005 estão alicerçadas na base de conhecimentos proposta por Shulman (1986) - conhecimento do conteúdo, conhecimento pedagógico do conteúdo e conhecimento curricular - e no TPACK (Mishra \& Koehler, 2006).

Assim, TDIC estão incorporadas à formação do futuro professor, em diferentes disciplinas, específicas e pedagógicas, promovendo a interação entre três corpos de conhecimentos - curricular, pedagógico e tecnológico - cada um deles influenciando diretamente o outro (Cibotto \& Oliveira, 2017), promovendo o desenvolvimento do Conhecimento Tecnológico e Pedagógico do Conteúdo (TPACK).

A visão dos egressos do curso, abordada na seção seguinte, evidencia a contribuição das diferentes vivências durante o processo de formação inicial na constituição do TPACK.

\section{A formação para o uso das TDIC na visão dos egressos}

Partindo do pressuposto de que a visão dos egressos sobre a formação vivenciada apresenta elementos importantes para análise da incorporação das TDIC no curso, foi elaborado um questionário no Google Forms e enviado aos egressos do período 2006-2017.

Constituído de três partes, o questionário foi composto por questões abertas e fechadas. A primeira parte, intitulada "Perfil", objetivou colher informações sobre o egresso, tais como: nome completo; ano de conclusão do curso; realização de outro curso de graduação e/ou cursos de pós-graduação, lato sensu ou stricto sensu; tempo de atuação profissional em instituições públicas e/ou privadas de Educação Básica e Ensino Superior; e, a percepção sobre o que são Tecnologias Digitais de Informação e Comunicação (TDIC).

Intitulada "Formação", a segunda buscou obter informações sobre a experiência do egresso com as TDIC durante o curso, de modo geral, e em relação às disciplinas "Informática no Ensino da Matemática” e/ou "Ensino de Matemática por Múltiplas Mídias", que mobilizam o Conhecimento Tecnológico Pedagógico de Conteúdo dos futuros 
professores. Para tanto, perguntamos aos egressos em quais disciplinas utilizaram TDIC, quais foram os recursos utilizados, a natureza das atividades desenvolvidas, bem como a contribuição de tais disciplinas para sua formação. Ainda sobre a formação, solicitamos aos egressos que justificassem os motivos pelos quais eles se sentem ou não preparados para usar TDIC no ensino de Matemática.

A parte III, "Prática profissional", buscou identificar, por meio de uma escala de frequência, a contribuição das experiências e aprendizagens envolvendo TDIC no curso e nas disciplinas "Informática no Ensino da Matemática" e/ou "Ensino de Matemática por Múltiplas Mídias", para uma visão crítica sobre as possibilidades de uso das TDIC no processo de ensino e aprendizagem da Matemática. Nesse sentido, os egressos foram convidados a relatar uma experiência de uso de TDIC em suas aulas.

A rede social Facebook foi utilizada para contactar os egressos e solicitar seus endereços eletrônicos. O link que dá acesso ao questionário foi enviado a 332 dos 385 formados no período 2006-2017, que atenderam a solicitação. Os 90 egressos respondentes, foram identificados pela letra E, indicando a palavra "egresso", seguida do número do questionário, por exemplo, E1, E2, E3, e assim, sucessivamente, até E90. As respostas das questões fechadas foram organizadas em tabelas com frequências e respectivos percentuais e as respostas das questões abertas foram categorizadas utilizando análise de conteúdo (Bardin, 2016).

A seguir, apresentamos a análise dos dados produzidos.

Dos egressos respondentes, $60(66,6 \%)$ realizaram pós-graduação, lato sensu ou stricto sensu, e desses, apenas três cursaram especialização. Dos demais, 32 (35,5\%) cursaram Doutorado e 25 (27,7\%), Mestrado.

Ao avaliarem a formação para o uso das TDIC vivenciada no curso, 66 (73,3\%) participantes indicaram que as experiências e aprendizagens envolvendo tecnologias contribuíram para o estudo e a reflexão crítica sobre o uso de tecnologias no processo de ensino e aprendizagem da Matemática.

Quando questionados sobre as disciplinas do curso em que utilizaram as TDIC, os respondentes fizeram 193 indicações envolvendo diferentes disciplinas. As mais destacadas foram "Informática no Ensino de Matemática" (19,7\%) seguida de "Laboratório de Ensino de Matemática I" (16,6\%), "Laboratório de Ensino de Matemática II” (16,1\%) e "Programação Orientada a Sistemas de Computação Simbólica”/“Cálculo Numérico I” (12,9\%). Com 
percentuais menores, despontaram disciplinas, tais como "Cálculo Diferencial e Integral", "Fundamentos de Matemática Elementar", "Probabilidade e Estatística", "Estágios Curriculares Supervisionados", "Didática", "Psicologia da Educação", "Organização do Trabalho Escolar", "Libras" e "Seminários Especiais". As respostas fornecidas pelos egressos abordam o conjunto de conhecimentos - curricular, pedagógico e tecnológico -, confirmando a interação entre tais conhecimentos na perspectiva do TPACK.

Em relação às disciplinas do curso que promovem a reflexão e estudos sobre o uso de TDIC no ensino, a saber, "Informática no Ensino da Matemática" e/ou "Ensino de Matemática por Múltiplas Mídias”, 78 (86,6\%) egressos indicaram que elas contribuíram para a formação, sendo que 51 das justificativas ressaltaram a relação teoria e prática proporcionada pelas disciplinas, nas quais tiveram a oportunidade de vivenciar o uso de TDIC no contexto da escola pública, o que possibilitou a reflexão sobre abordagens pedagógicas com TDIC para ensinar Matemática. Como exemplo, podemos citar a justificativa de três egressos:

A partir desta disciplina, ficaram claras a possibilidade e a necessidade do uso das TIC no processo de ensino/aprendizagem e de que forma elas podem contribuir para esse processo. Acredito que uma contribuição importante foi nos apresentar que, embora tenhamos tido somente aulas tradicionais (sem o uso de TIC) durante nossa vida escolar, podíamos utilizar esses recursos e adequar nossas aulas, como futuros professores, à realidade atual, fazendo uso dessas novas possibilidades. (E07).

Foi essencial ter conhecido as TICs durante a graduação e saber seus potenciais e limitações, pois hoje, na minha atuação como professor, consigo discernir sobre o melhor momento para utilizá-las ou não. Tenho usado muitas TICs na minha prática docente: softwares e sites da internet são predominantes, além do Moodle, para disponibilização de material e aplicação de atividades/questionários a distância. (E03).

No meu ano a disciplina visava articular as TIC's no desenvolvimento de um projeto na escola. Na minha opinião esse foi o maior ganho com a disciplina, aprendemos as potencialidades dos recursos, e como utilizá-los como um meio e não como fim na prática pedagógica. (E66).

As justificativas ressaltam a importância de abordar as TDIC no curso de formação inicial de professores, mobilizando não apenas o Conhecimento Tecnológico e/ou o Conhecimento Tecnológico Pedagógico, mas, também o Conhecimento Tecnológico Pedagógico de Conteúdo. Tal importância foi apontada por E03 ao mencionar que consegue discernir o melhor momento para utilizar as TDIC em sua prática profissional como docente, e por E66 ao indicar que aprendeu a utilizar as TDIC como um meio e não como fim em sua prática profissional. 
Ainda analisando as contribuições dessas duas disciplinas, 13 egressos indicaram que elas forneceram subsídios para a sua prática, como evidenciam as justificativas a seguir.

Foi uma disciplina fundamental para minha tomada de decisão quanto à profissão e à continuidade de meus estudos na área da Educação Matemática. Ao problematizar a tecnologia como promotora e provocadora de ideias e reflexões em meio ao processo de ensinar e aprender matemática, foi neste espaço da formação inicial que compreendi a profissão docente diretamente relacionada às condições que se oferece ao aluno para compreensão e significação do conhecimento matemático. (E32).

A disciplina contribuiu muito para nossa formação, pois possibilitou a discussão sobre autores da área, apresentou novos softwares matemáticos e também nos auxiliou a diferenciar os softwares que são potencialmente efetivos no ensino de matemática, daqueles que são meramente instrucionistas. Ajudou-nos a enxergar a necessidade do feedback e do registro no processo de aprendizagem, apontando, neste contexto, algumas linguagens de programação que colocam o estudante a pensar sobre o que está aprendendo de uma forma diferente, tendo em vista a metacognição. Além disso, foi de grande valia para nossa formação, porque nos possibilitou discussões sobre os obstáculos que são encontrados no chão da escola, que, muitas vezes, dificultam o trabalho com as TICs em sala de aula. (E56).

Além disso, dez respondentes ressaltaram que as duas disciplinas possibilitaram contato com diferentes recursos tecnológicos, como pode ser observado a seguir.

Hoje posso ministrar aulas com o auxílio de múltiplas tecnologias, não só lousa e giz, como ministro aulas de Geometria como matéria separada da Matemática, a utilização do GeoGebra que conheci nessa matéria me ajuda muito. (E85).

Elas contribuíram de maneira significativa, pois eu não tinha conhecimento dessas técnicas de ensino. Utilizando um software é muito mais fácil trabalhar o abstrato, porque ele passa a ser concreto de uma maneira lúdica, o aluno passa a dar significado para o que ele está aprendendo, e isso na minha formação é de grande importância, pois eu tenho que buscar meios de fazer a matemática se tornar menos assustadora e mais interessante, e as Tics, é o que mais se aproxima da realidade do aluno e ainda faz com que o aluno se torne agente do seu próprio conhecimento, deixando o professor como mediador dessa interação. (E65).

Pode-se perceber que a utilização dos softwares durante as aulas me possibilitou a ter a autonomia em buscar, trabalhar e construir o próprio conhecimento. (E51).

Por ter usado de forma variada durante minha formação a nivel de graduação, tendo experimentado não somente um tipo de tecnologia, isso me possibilitou tentar ensinar matemática de maneiras variadas. (E50).

As justificativas apresentadas revelam o movimento vivenciado pelos licenciandos, na constituição dos conhecimentos bases da docência. Evidenciam, ainda, a contribuição das disciplinas "Informática no Ensino da Matemática" e/ou "Ensino de Matemática por Múltiplas Mídias" para a reflexão sobre a prática e os diferentes usos de recursos tecnológicos para ensinar Matemática, desenvolvendo o Conhecimento Tecnológico Pedagógico de Conteúdo (TPACK).

Quanto aos 12 egressos para os quais as disciplinas não contribuíram, sete concluíram o curso em 2006 ou 2007, quando a disciplina “Ensino de Matemática por Múltiplas Mídias” 
era optativa e não foi por eles cursada; três não tiveram experiência docente e dois justificaram a não contribuição pela natureza dos softwares utilizados.

Em relação a estar preparado para utilizar as TDIC no ensino de Matemática, dos 90 egressos respondentes, $58(64,4 \%)$ indicaram que se sentem preparados e 32 deles apresentaram como justificativa a qualidade da formação inicial que tiveram, como pode ser observado nos excertos a seguir:

Durante a graduação, acredito que tive uma boa preparação quanto ao uso desse tipo de recursos. Atualmente, não apenas me sinto preparado, como faço uso destas tecnologias durante as minhas aulas (...). (E07).

Devido a formação sólida e eficaz que tive em relação as TIC'S. (E35).

Pois acredito na formação que tive e penso que tenho capacidade para trabalhar com as Tics na escola. Também porque enquanto professor que sou, preocupado com o aprendizado dos meus estudantes, preciso investir em diversas abordagens do ensino de Matemática para alcançar meus objetivos. Sinto-me preparado para o desafio de usar TIC no ensino de Matemática, mas consciente de que um professor está imerso num constante processo de aprendizado. (E56).

Justificativas como as dos egressos E07, E35, E56 revelam que eles se sentem preparados em relação ao uso das TDIC, reconhecendo que a formação é boa, sólida e eficaz.

No entanto, 32 egressos $(35,5 \%)$ indicaram que não se sentem preparados para utilizar as TDIC em aulas de Matemática. Cabe ressaltar que dentre eles, 17 não possuíam experiência docente na Educação Básica ou Ensino Superior no momento que responderam o questionário. Dentre as justificativas apresentadas, destacam-se 16 por mencionarem falta de formação/preparo e a falta de conhecimento, como exemplificadas a seguir.

Porque acho que ainda é preciso um aprofundamento muito grande na forma de usar para que não fique algo como "usar por usar". (E57).

Porque eu acho que eu tenho muito o que aprender e inovar. (E53).

Quanto à atuação profissional, $51(56,7 \%)$ egressos possuem experiência nos anos finais do Ensino Fundamental, 46 (51,1\%) no Ensino Médio e 33 (36,7\%) no Ensino Superior, público e/ou privado. Dos 90 participantes da pesquisa, 59 (66\%) indicaram utilizar as TDIC para ensinar Matemática. O uso mais frequente é de softwares educacionais, como, por exemplo, softwares de Geometria Dinâmica e de construção de gráficos. Mas, foram citados, também, uso de vídeos, apresentação de slides, jogos, lousa digital, sites para pesquisa, ambientes virtuais de aprendizagem (AVA), aplicativos de celulares, calculadoras, objetos de aprendizagem (applets) e, ainda, criação de vídeos e construção de blogs. Chama atenção o fato de $23(25,5 \%)$ participantes indicarem que recorrem às atividades 
desenvolvidas e textos discutidos na disciplina Informática no Ensino da Matemática e/ou Ensino de Matemática por múltiplas mídias para planejar suas aulas.

Para melhor entender como os egressos utilizam as TDIC em sua atuação profissional, solicitamos que relatassem alguma experiência de uso em suas aulas, que consideram interessante, contemplando: nível de ensino, conteúdo matemático abordado, TDIC utilizada, metodologia empregada, avaliação e resultados alcançados.

A seguir, apresentamos alguns relatos dos egressos investigados sobre o uso de TDIC em sua prática profissional.

Trabalho o Geogebra no ensino médio para falar sobre funções. Deixo os alunos conhecerem o software, explico alguns comandos para plotar os gráficos e eles vão realizando as atividades propostas e percebendo o que acontece com cada função ao ser plotada e ao mudar algum parâmetro na função. (E37).

$9 o$ ano, reflexão e translação de formas geométricas, uso de aplicativo específico desenvolvido para iPad. Início com retomada de pontos no plano e representações no plano. O primeiro contato com o conteúdo já foi através do aplicativo. [...] Alguns alunos com maiores dificuldades motoras tiveram tempo diferenciado para desenvolver as atividades. Compreenderam e aplicaram o conteúdo de forma satisfatória. (E11).

Destaco como experiência interessante algumas ações desenvolvidas no Ensino Médio $\left(2^{\circ}\right.$ ano), em uma escola particular, a respeito da discussão de sistemas lineares. Mesmo relativamente "preso" à um sistema de ensino apostilado, as discussões sobre a caracterização de sistemas lineares e a representação gráfica dos mesmos $(2 \times 2 ; 3 \times 3)$ com o uso dos software Máxima e Geogebra, possibilitou aos alunos realmente vivenciarem a "discussão de sistemas lineares" descrita no material didático. [...] A aula foi desenvolvida com o uso do recurso da lousa digital, dentro da sala convencional da turma. [...] Após a resolução de alguns dos exercícios "clássicos" de classificação e resolução de sistemas lineares e esse problema específico citado acima, as discussões foram bem interessantes e os resultados dessa ação refletiram nas demais atividades avaliatórias desse componente. Me recordo que os alunos baixaram o software para conferirem a resolução de alguns sistemas (previstos no caderno de exercícios do sistema de ensino que a escola utilizava) $e$ encontrando erros no material inclusive. Nós, até enviamos a editora responsável essa questão. Foi uma experiência positiva que me recordo até hoje, e na medida do possível, tento reutilizar. (E31).

É possível notar nos relatos o uso de TDIC em diferentes contextos e níveis de ensino, em instituições públicas e privadas, para trabalhar conteúdos matemáticos diversos utilizando recursos e metodologias diversificados. Essa diversidade de usos e contextos revela domínio de diferentes conhecimentos, a saber, conhecimento tecnológico, pedagógico e de conteúdo, que constituem o TPACK.

\section{Considerações finais}

O exposto neste artigo revela um projeto diferenciado de formação de professores de Matemática, no qual a tecnologia permeia todo o processo formativo, estimulando, 
motivando e oportunizando diferentes formas de uso crítico das TDIC. Nesse processo, o aluno aprende de e sobre Matemática e ressignifica suas experiências ao refletir sobre o uso das TDIC no processo de ensinar e aprender.

Egressos que atuam na Educação Básica, assim como o universo daqueles que cursaram pós-graduação atestam a riqueza do processo formativo aqui analisado. As justificativas revelam uma visão crítica do uso das TDIC no processo de ensino e aprendizagem, mesmo daqueles alunos que tiveram somente aulas tradicionais na sua vida escolar, como indicado por E07. Revelam, ainda, a percepção "de que um professor está imerso num constante processo de aprendizado" (E56). Observamos, assim, indícios de que o curso "abalou" os licenciandos, ainda que Tardif (2000) afirme que "a formação para o magistério tem um impacto pequeno sobre o que pensam, crêem e sentem os alunos antes de começar" (Tardif, 2000, p. 20).

Para $86,6 \%$ dos egressos respondentes do questionário, as disciplinas "Ensino de Matemática por Múltiplas Mídias" e "Informática no Ensino de Matemática" contribuíram na sua atuação profissional com tecnologia, destacando como um ponto alto das disciplinas o projeto de intervenção desenvolvido na Educação Básica, indicando que vivenciaram um conjunto de experiências que deram respaldo à sua prática.

As justificativas revelam, ainda, que o curso como um todo e, mais especificamente, as disciplinas que problematizam o ensino de Matemática com TDIC, promovem uma relação entre teoria e prática que se estreita na vivência do projeto de intervenção. Em nossa concepção, isso evidencia o conhecimento do futuro professor situado na prática, ou seja, o conhecimento-da-prática, como apresentam Cochran-Smith e Lytle (1999).

A preocupação com a formação para o uso das TDIC, presente há 15 anos no curso, bem como as pesquisas sobre esse tema, tem fundamentado as alterações curriculares, mesmo antes do que estabeleceu a legislação sobre formação de professores. Nessa perspectiva inovadora, a partir de resultados de pesquisas, o curso tem proporcionado ao futuro professor, em diferentes disciplinas, o desenvolvimento do pensamento computacional, que somente em 2018 surge na BNCC, como uma habilidade a ser desenvolvida na Educação Básica.

Atualmente, duas entre dez competências gerais da BNCC apresentam novas relações da tecnologia com o processo de ensino e aprendizagem, sendo uma focada no uso de diferentes linguagens para expressar e compartilhar informações e a outra, focada no uso 
da tecnologia com um viés crítico. No que se refere às competências e habilidades específicas da Matemática, a tecnologia se faz presente em duas competências dessa unidade curricular. Uma delas indica a articulação de conhecimentos matemáticos com a implicação da tecnologia no mundo do trabalho. A outra, envolve o planejamento e execução de ações que articulam a criação e a utilização de aplicativos e jogos digitais, entre outros recursos. O documento salienta, também, a importância do trabalho com algoritmos e fluxogramas nas aulas de Matemática, associados ao pensamento computacional (Brasil, 2018), o que tem sido contemplado no curso.

Valente (2016) apresenta diversas perspectivas de integração do pensamento computacional no contexto educacional brasileiro, chamando a atenção para a formação de professores "para que possam desenvolver atividades relacionadas ao pensamento computacional” (Valente, 2016, p. 866). Javaroni e Zampieri (2018) também apontam o pensamento computacional como uma temática a ser abordada na formação inicial e continuada de professores de Matemática, além do que outros pesquisadores vêm desenvolvendo na formação de professores com TDIC.

Pesquisadores em todo o mundo têm investigado o pensamento computacional e seu desenvolvimento no contexto educacional nos processos de ensino e aprendizagem e leis oficiais de Educação de diversos países, como Estados Unidos da América, Inglaterra, França, Coréia do Sul, Finlândia, Argentina e Alemanha, entre outros, já exigem o desenvolvimento computacional na Educação Básica (Brackmann, 2017).

Apoiados em Brackmann (2017), Furber (2012), Javaroni e Silva (2019) e Silva (2018), compreendemos que o pensamento computacional está associado à organização do pensamento humano de modo a utilizar os fundamentos da Computação na resolução de problemas. Trata-se de "um conjunto de processos de pensamento que desenvolvemos para resolver um determinado problema de forma que busquemos reconhecer padrões, realizar decomposições do problema em partes menores, realizar um raciocínio algorítmico e abstrato" (Javaroni \& Silva, 2019, p. 166).

No curso aqui investigado, o licenciando pode se apropriar de noções sobre lógica de programação no início da jornada de formação, ao cursar a disciplina "Programação Orientada a Sistemas de Computação Simbólica"/“Cálculo Numérico I”. Ao dominar os fundamentos da Computação, o estudante pode desenvolver o pensamento algorítmico, e por consequência, reconhecer padrões e decomposição, que estão vinculados à criação de 
algoritmos, utilizando-os na resolução de problemas de disciplinas específicas do curso. Essa vivência no processo formativo constitui o conhecimento do conteúdo, o conhecimento pedagógico do conteúdo e o conhecimento tecnológico.

No último ano do curso, na disciplina "Informática no Ensino da Matemática", quando o estudante reflete criticamente sobre a incorporação de diferentes TDIC para ensinar Matemática, envolvendo inclusive softwares de programação computacional, e concretiza esse estudo por meio de uma intervenção na escola pública, é proporcionado a ele a apropriação do conhecimento pedagógico vinculado ao pensamento computacional, consolidando a formação docente proposta pelo curso, na perspectiva do TPACK. Com isso, desde 2005, a disciplina promove o desenvolvimento de duas das dez competências presentes na BNCC de 2018, quanto as novas relações da tecnologia com o processo de ensino e aprendizagem. Desse modo, mais uma vez, fica evidente a preocupação do curso com a formação do futuro professor quanto a incorporação das TDIC na sua atuação profissional.

Assim, antes mesmo da publicação das Diretrizes Curriculares Nacionais e Base Nacional Comum para a Formação Inicial e Continuada de Professores da Educação Básica, o curso já proporcionava aos futuros professores vivências que envolvem abordagens pedagógicas com TDIC, demonstrando uma visão e preocupação em oportunizar experiências de aprendizagem que estimulam uma postura crítica e investigativa e uma prática inovadora, com tecnologia.

\section{Referências}

Almeida, H. R. F. L. (2015). Das tecnologias às tecnologias digitais e seu uso na Educação Matemática. Nuances: estudos sobre Educação, 26(2), 222-239. https://doi.org/10.14572/nuances.v26i2.2831.

Ball, D. (1988). Knowledge and reasoning in mathematical pedagogy: Examining what prospective teachers bring to teacher education [doctoral thesis, Michigan State University]. Repositório:

http://citeseerx.ist.psu.edu/. http://citeseerx.ist.psu.edu/viewdoc/download?doi=10.1.1.739.3592\&rep=rep1\&type=pdf.

Bardin, L. (2016). Análise de conteúdo. Edições 70.

Barth, B. (1993). O saber em construção: Para uma pedagogia da compreensão. Instituto Piaget.

Brackmann, C. P. (2017). Desenvolvimento do pensamento computacional através de atividades desplugadas na Educação Básica [tese de doutorado, Universidade Federal do Rio Grande do Sul]. Repositório: https://lume.ufrgs.br/. https://lume.ufrgs.br/bitstream/handle/10183/172208/001054290.pdf?sequence=1\&isA llowed $=\mathrm{y}$. 
Brasil. (1996, 20 de dezembro). Lei $n^{\circ} .9 .394$ de 20. Estabelece as diretrizes e bases da educação nacional. http://www.planalto.gov.br/ccivil 03/leis/19394.htm.

Brasil. (1998). Parâmetros Curriculares Nacionais: Matemática /Secretaria de Educação Fundamental. Secretaria de Educação Fundamental. MEC/SEF.

Brasil. (1998). Resolução CEB $n^{\circ}$. 3/1998. Institui as Diretrizes Curriculares Nacionais para o Ensino Médio. http://portal.mec.gov.br/cne/arquivos/pdf/rceb03 98.pdf.

Brasil. (2001a, 9 de janeiro). Lei $n^{\circ}$ 010172. Aprova o Plano Nacional de Educação e dá outras providências. Diário Oficial da União - Seção 1 - 10/1/2001, Página 1 (Publicação Original). http://portal.mec.gov.br/arquivos/pdf/L10172.pdf.

Brasil. (2001b, 5 de março). Parecer CNE/CES 1302/2001. Diretrizes Curriculares Nacionais para os Cursos de Matemática, Bacharelado e Licenciatura. Despacho do Ministro em 4/3/2002, publicado no Diário Oficial da União de 5/3/2002, Seção 1, p. 15. http://portal.mec.gov.br/cne/arquivos/pdf/CES13022.pdf.

Brasil. (2002a, 18 de fevereiro). Resolução CNE/CP 1. Institui as Diretrizes Curriculares Nacionais para a Formação de Professores da Educação Básica, em nível superior, curso de licenciatura, de graduação plena. Diário Oficial da União, Brasília, 9 de abril de 2002. Seção 1, p. 31. Republicada por ter saído com incorreção do original no D.O.U. de 4 de março de 2002. Seção 1, p. 8. http://portal.mec.gov.br/seesp/arquivos/pdf/res1_2.pdf.

Brasil. (2002b, 18 de fevereiro). Resolução CNE/CP 2. Institui a duração e a carga horária dos cursos de licenciatura, de graduação plena, de formação de professores da Educação Básica em nível superior. Diário Oficial da União, Brasília, 4 de março de 2002. Seção 1, p. 9. http://portal.mec.gov.br/cne/arquivos/pdf/CP022002.pdf.

Brasil. (2007, 5 de dezembro). Parecer CNE/CP 9. Reorganização da carga horária mínima dos cursos de Formação de Professores, em nível superior, para a Educação Básica e Educação Profissional no nível da Educação Básica. Aprovado em 5 de dezembro de 2007. Aguardando homologação. http://portal.mec.gov.br/cne/arquivos/pdf/2007/pcp009 07.pdf.

Brasil. (2015, 1 de julho). Resolução CNE/CP $n^{o}$. 2. Diretrizes Curriculares Nacionais para a Formação Inicial em nível superior (cursos de licenciatura, cursos de formação pedagógica para graduados e cursos de segunda licenciatura) e para a formação continuada. Diário Oficial da União, Brasília, 2 de julho de 2015. Seção 1, pp. 8-12. http://portal.mec.gov.br/docman/agosto-2017-pdf/70431-res-cne-cp-002-03072015pdf/file.

Brasil. (2018). Base Nacional Curricular Comum - BNCC. Ministério da Educação http://basenacionalcomum.mec.gov.br/images/BNCC_EI_EF_110518_versaofinal_s ite.pdf.

Brasil. (2019, 20 de dezembro). Resolução CNE/CP $n^{\circ}$ 2. Define as Diretrizes Curriculares Nacionais para a Formação Inicial de Professores para a Educação Básica e institui a Base Nacional Comum para a Formação Inicial de Professores da Educação Básica (BNC-Formação). Diário Oficial da União, Brasília, de 20 de dezembro de 2019, Seção 1, pág. 142. http://portal.mec.gov.br/docman/dezembro-2019-pdf/135951-rcp002-19/file.

Cibotto, R. A. H. \& Oliveira, R. M. A. (2017). TPACK - Conhecimento tecnológico e pedagógico do conteúdo: Uma revisão teórica. Imagens da Educação, 7(2), 11-23. https://doi.org/10.4025/imagenseduc.v7i2.34615. 
Cochran-Smith, M. \& Lytle, S. L. (1999). Relationships of knowledge and practice: Teacher learning in communities. Review of Research in Education, 24(8), 249-305. https://doi.org/10.3102/0091732X024001249.

Coll, C., Mauri, T. \& Onrubia, J. (2010). A incorporação das tecnologias da informação e da comunicação na educação. Em C. Coll e C. Monereo (Eds.), Psicologia da Educação Virtual: Aprender a ensinar com as Tecnologias da Informação e da Comunicação (pp. 66-93). Artmed.

Furber, S. (2012). Shut down or restart? - The way forward for computing in UK schools. The Royal Society.

Fürkotter, M. \& Morelatti, M. R. M. (2007). A articulação entre teoria e prática na formação inicial de professores de matemática. Educação Matemática Pesquisa, 9(2), 319-334. https://revistas.pucsp.br/emp/article/view/906.

Javaroni, S. L. \& Silva, E. C. (2019). Pensamento computacional nos anos finais do ensino fundamental. In M. A. Rossi e E. P. G. Serrano (Eds.), Educação e Sociedade (pp. 147167). Canal 6 Editora.

Javaroni, S. L. \& Zampieri, M. T. (2018). Tecnologias digitais nas aulas de Matemática: Um panorama acerca das escolas públicas do Estado de São Paulo. Livraria da Física.

Kenski, V. M. (2013). Tempo Docente. Papirus.

Koehler, M. J., Mishra, P., Akcaoglu, M. \& Rosenberg, J. M. (2014). The technological pedagogical content knowledge framework for teachers and teacher educators. In J. M. Spector., M. D. Merrill., J. V. Merriënboer \& M. P. Driscoll (Eds.), Handbook of Research on Educational Communications and Technology (pp. 101-111). Springer.

Lopes, R. P. (2010). Formação para uso das Tecnologias Digitais de Informação e Comunicação nas licenciaturas das universidades estaduais paulistas [dissertação de mestrado, Universidade Estadual Paulista]. Repositório: https://repositorio.unesp.br/. https://repositorio.unesp.br/handle/11449/92296.

Lopes, R. P. (2014). Concepções e práticas declaradas de ensino e aprendizagem com TDIC em curso de Licenciatura em Matemática [tese de doutorado, Universidade Estadual Paulista]. Repositório: https://repositorio.unesp.br/. https://repositorio.unesp.br/handle/11449/122253.

Lopes, R. P. \& Fürkotter, M. (2016). Formação inicial de professores em tempos de TDIC: Uma questão em aberto. Educação em Revista, 32(4), 269-296. https://doi.org/10.1590/0102-4698150675.

Marcelo Garcia, C. (1999). Formação de professores - Para uma mudança educativa. Porto Editora.

Mishra, P. \& Koehler, M. J. (2006). Technological pedagogical content knowledge: A framework for teacher knowledge. Teachers College Record, 108(6), 1017-1054. http://one2oneheights.pbworks.com/f/MISHRA_PUNYA.pdf.

Paiva, R., Toriani, S. \& Lucio, V. R. (2012). Formação docente para o uso das tecnologias digitais. Em E. L. D. Silva (Ed.), Mídia-Educação: Tecnologias digitais na prática do professor (pp. 105-116). CRV.

Perrenoud, P. (2000). Dez novas competências para ensinar. Artmed Editora.

Pires, C. M. C. (2002). Reflexões sobre os cursos de Licenciatura em Matemática, tomando como referência as orientações propostas nas Diretrizes Curriculares Nacionais para a 
formação de professores da Educação Básica. Educação Matemática em Revista, 9(11), 44-56.

Santos, L. C., Costa, D. E. \& Gonçalves, T. O. (2017). Uma reflexão acerca dos conhecimentos e saberes necessários para a formação inicial do professor de Matemática. Educação Matemática Pesquisa, 19(2), 265-290. https://doi.org/10.23925/19833156.2017v19i2p265-290.

São Paulo (Estado). (2012, 3 de fevereiro). Deliberação 111/2012. Conselho Estadual de Educação. Diário Oficial do Estado em 03/02/2012 - Seção I - Página 46. http://www.ceesp.sp.gov.br/ceesp/textos/2012/Del\%20CEE\%20111-12\%20$\% 20 \mathrm{NR} \% 20 \mathrm{da} \% 20154 . p d f$.

São Paulo (Estado). (2014, 13 de junho). Deliberação 126. Conselho Estadual de Educação. Altera dispositivos da Deliberação 111/2012. Diário Oficial do Estado em 05/6/2014 Seção I p. 28. http://www.ceesp.sp.gov.br/ceesp/cons_simples_listar.php?id_atos $=72780 \&$ acao $=$ entrar.

São Paulo (Estado). (2017, 31 de maio). Deliberação 154. Conselho Estadual de Educação. Dispõe sobre alteração da Deliberação CEE $n^{\circ} 111 / 2012$. Diário Oficial da União Seção I de 07 de junho de 2017. http://www.anped.org.br/sites/default/files/images/65106 delib-154-17-indic-160-17-.pdf.

Shulman, L. S. (1986). Those who Understand: Knowledge growth in teaching. Educational Research, 15(2), 4-14. https://doi.org/10.3102/0013189X015002004.

Silva, E. C. (2018). Pensamento computacional e a formação de conceitos matemáticos nos anos finais do Ensino Fundamental: Uma possibilidade com kits de robótica [dissertação de mestrado, Universidade Estadual Paulista]. Repositório: https://repositorio.unesp.br/. https://repositorio.unesp.br/bitstream/handle/11449/180525/silva_ec_me_rcla.pdf?sequ ence $=3 \&$ isAllowed $=y$.

Tardif, M. (2000). Saberes profissionais dos professores e conhecimentos universitários. Elementos para uma epistemologia da prática profissional dos professores e suas consequências em relação à formação para o magistério. Revista Brasileira de Educação, (13), http://anped.tempsite.ws/novo_portal/rbe/rbedigital/RBDE13/RBDE13 05_MAURICE TARDIF.pdf.

Valente, J. A. (1999). Informática na educação no Brasil. Em J. A. Valente (Ed.), $O$ computador na sociedade do conhecimento (pp. 1-27). Unicamp/NIED.

Valente, J. A. (2016). Integração do pensamento computacional no currículo da educação básica: Diferentes estratégias usadas e questões de formação de professores e avaliação $\begin{array}{llll}\text { do aluno. Revista } & \text { e-Curriculum, } & \text { 14(03), }\end{array}$ https://revistas.pucsp.br/curriculum/article/view/29051.

Valente, J. A. (2018). Inovação nos processos de ensino e de aprendizagem: O papel das tecnologias digitais. Em J. A. Valente, F. M. P. Freire e F. L. Arantes (Eds.), Tecnologia e Educação: Passado presente e o que está por vir (pp. 17-41). Unicamp/NIED. https://odisseu.nied.unicamp.br/wp-content/uploads/2018/11/Livro-NIED-2018final.pdf. 
Autores

Monica Fürkotter

Doutora em Ciências (Matemática: Análise) pelo Instituto de Ciências Matemáticas de São Carlos (Brasil). Docente aposentada da Universidade Estadual Paulista (UNESP), Câmpus de Presidente Prudente (Brasil). Docente do Programa de Pós-graduação em Educação da Universidade do Oeste Paulista (Unoeste, Brasil). Temas de pesquisa: Formação inicial e continuada de professores; Ensino e aprendizagem de Matemática; Tecnologias Digitais de Informação e Comunicação na Educação; Avaliação. E-mail: monicaf@unoeste.br

Maria Raquel Miotto Morelatti

Doutora em Educação (Currículo) pela Pontifícia Universidade Católica de São Paulo (PUC/SP, Brasil). Professora assistente doutora junto ao Departamento de Matemática e Computação (DMC) e coordenadora do Programa de Pós-Graduação em Educação (PPGE) da Faculdade de Ciências e Tecnologia (FCT), da Universidade Estadual Paulista (UNESP), Câmpus de Presidente Prudente (Brasil). Temas de pesquisa: Processos formativos; Ensino e aprendizagem de Matemática; Formação de professores de matemática; Novas tecnologias educacionais. E-mail: maria.raquel@unesp.br

Eliel Constantino da Silva

Mestre em Educação Matemática pela Universidade Estadual Paulista (UNESP/Câmpus

Rio Claro, Brasil). Doutorando em Educação Matemática pela Universidade Estadual Paulista (UNESP/Câmpus Rio Claro). Professor do Colégio Internacional Radial, Coordenador de projetos da Foreducation EdTech, Google Educator (Nível 1 e Nível 2).

Temas de pesquisa: Educação Matemática; Pensamento Computacional; Robótica; Programação Computacional; Tecnologias Digitais de Informação e Comunicação na Educação; Ensino e Aprendizagem; Teoria Histórico-Cultural; Formação de conceitos; Formação de Professor de Matemática. E-mail: elielconstantinosilva@gmail.com 